\title{
MB2 in Maxillary Molars: Location and Alternatives for Treatment
}

\author{
Renata Soledade Signori ${ }^{1}$ and Larissa Magnus Klassmann ${ }^{2 *}$ \\ ${ }^{1}$ Pós Graduate student of the Endodontics Specialization at Faculdade Menino Deus/FAMED in an educational agreement \\ with the Postgraduate Dental Institute / Odontopós, Brazil
}

${ }^{2} \mathrm{PhD}$ in Dentistry, Professor and Coordinator of the Endodontics Specialization at Faculdade Menino Deus/FAMED in an educational agreement with the Postgraduate Dental Institute / Odontopós, Brazil

*Corresponding author: Jacob Greenwood, Department of Biological Systems Engineering, University of Nebraska, Lincoln 68583, USA

\begin{abstract}
ARTICLE INFO
Received: 幽 September 09, 2019

Published: September 16, 2019

Citation: Renata Soledade Signori, Larissa Magnus Klassmann. MB2 in Maxillary Molars: Location and Alternatives for Treatment. Biomed J Sci \& Tech Res 21(3)-2019. BJSTR. MS.ID.003592.

ABSTRACT

The success of endodontic treatment depends on the location of all root canals, so that they can be cleaned, shaped and filled. Therefore, the objective of this article was to review the literature on existing alternatives to facilitate the localization and negotiation of second canal in mesiobuccal root (MB2) and to illustrate, through two clinical cases, some of these alternatives. In case one we show the management of a biopulpectomy of an upper molar. In the second case, a pulp necrosis, with fistula in which there was only regression after localization, negotiation and intracanal medication of MB2. It should be emphasized that in the maxillary molars, the endodontist should always go in search of MB2, using all available tools, accessible and necessary for each case and this conduct is determinant for the endodontic success of many treatments.
\end{abstract}

Keywords: Endodontics; Maxillary First Molar; Secondary Mesiobuccal Canal (MB2)

\section{Introduction}

In endodontics, the maxillary first molars present a constant challenge, given the difficulty in locating and treating the fourth canal, called the second canal in mesiobuccal root or MB2 [1-3]. The MB2 starts from the pulp chamber at a steep mesial slope and then bends back distally, which makes its detection and negotiation challenging [4]. The inability to detect and treat this canal is the reason for many endodontic failures since there is a high incidence of localization of these canals in cases of retreatment followed by uncomplicated healing, which suggests that failure rates may correlate with the inability to detect additional channels in the first treatment [5-7]demonstrated that teeth with an untreated canal are $4.38 \%$ more likely to be associated with injuries. The study by Nascimento et al. [8] showed that the most frequent technical error in maxillary molars was not filling the MB2. It is important to remember that changes in endodontic access and detection techniques along with improvements in illumination and magnification have helped in locating and treating MB2 [9]. Many studies [10-12] have shown a significant increase in detection of these channels when we associate the Microscope (MO) with ultrasound. Cone Beam Computed Tomography has also been found to be of great importance in endodontics, including the detection of additional channels, as some studies $[2,13,14]$ have shown a significantly higher rate of MB2 when it was requested.

After the location of MB2, we have the challenge of exploring and negotiating this curved, narrow and often calcified channel. Not all additional channels can be negotiated [14-16]. Some work has shown alternative techniques for this approach such as using reciprocating [17-19] and rotating [20-23] instruments to exploit and achieve working length. It is also noted that operator experience increases the ability to locate and treat additional channels [24]. Given the above, this paper is justified due to the great difficulty in locating and accessing the MB2 in maxillary molars, as well as the need for the Endodontic Specialist to be updated on the tools that can assist in achieving the success of maxillary first molar treatment. The aim of this paper was to review the literature on existing alternatives to facilitate localization and negotiation of 
MB2 and to illustrate, through two clinical cases, some of these alternatives.

\section{Literature Review}

\section{Morphology of the First Maxillary Molar}

The buccal mesial root of the upper first molar contains a dual canal system (92\%) more often than a single canal (8\%) [14]. Also, this dual system has a single foramen approximately twice as often in proportion to the that two [1]. The prevalence of MB2 decreases as the root approaches the apical third and the older the patient, the less MB2 are found [3,25]. The MB2 entrance is small and not easily seen. It is often hidden under a dentin shoulder or calcifications in a small groove where selective dentin removal is often required [3]. Many studies have been done to give the clinician a geometric location of the MB2 [26,27] suggest using the center of the MB1 channel as a reference parameter and from this point explore $2.68 \mathrm{~mm}(+-0.49)$ in a palatal direction and $1.25(+-0.34)$ in the mesial direction.

\section{Microsonics Filosofy}

The use of microscope with ultrasound is called Microsonics Filosofy. Magnification, illumination and ultrasonic inserts significantly improves the operator's ability to identify and access root canal inputs [28-30]. A study of 150 patients showed a $36 \%$ to $72 \%$ increase in MB2 detection with the associated use of microscope with selective dentin removal [3]. Other studies $[10,29]$ also found a significant increase in MB2 detection rate with this association. Ultrasound has many important applications in endodontics, including the more conservative and safe selective removal of dentin, to have access to MB2, since we have been able to remove dental structure in hard places $[31,32]$.

\section{MB2 Negotiation and Preparation}

The use of rotary systems to prepare MB2 channel has been reported as a highly successful alternative [21-23]. Buchanan [20], describes a technique for calcified channels using the GT files system. According to this technique, the canals must first be emptied with hand files \# 0.8, \# 0.10 and \# 0.15 not to compress the contents of the canals in the apical region and after motorized instrumentation should be started from crown to apex in order to achieve the desired working length and taper. Zuolo et al. 17] studied the frequency at which Reciprocal 25 (VDW, Maillefer Germany) is able to explore and reach the working length of upper molar MB2. In this work, the manual technique was used with reference, and Reciprocal 25 was $32 \%$ more effective in trading. Reciprocal 25 , according to Zuolo et al. [17] acts as a hole opening instrument and its effectiveness can be explained by the high flexibility, cutting capacity and relative force on the tip.

\section{Clinical Case Report}

\section{Case 1}

Patient, MCKS, female, 18 years old, went to Endodontic Specialization to treat the first left maxillary molar. After clinical and radiographic examination (Figure 1) the diagnostic was irreversible pulpitis. Anesthesia was performed with Mepiadre (DFL, Rio de Janeiro, Brazil) absolute isolation, coronary opening, location of channels, and working length was performed with apex locator (Romiapex A-15, Romidan Ltd, Kiryat Ono, Israel). The MB2 was localized using the \# $0.10 \mathrm{C}$ pilot file (VDW, Munich, Germany). Cervical preparation was performed with Protaper Universal SX instrument (DentisplyMailefer, Switzerland) and chemicalmechanical preparation with reciprocating Wave One Gold Primary instrumentation (Dentisply-Mailefer, Switzerland), irrigation with $2.5 \%$ sodium hypochlorite. The smear layer was removed and then an intracanal medication with calcium hydroxide paste was applied (SS WHITE, Rio de Janeiro, Brazil) and the teeth was sealed with Glass Ionomer (SS WHITE, Rio de Janeiro, Brazil). In the second appointment, the palatine root has been expanded with Wave One Gold Large (Dentisply-Maillefer, Switzerland), smear layer was removed and obturation performed (Figure 2).

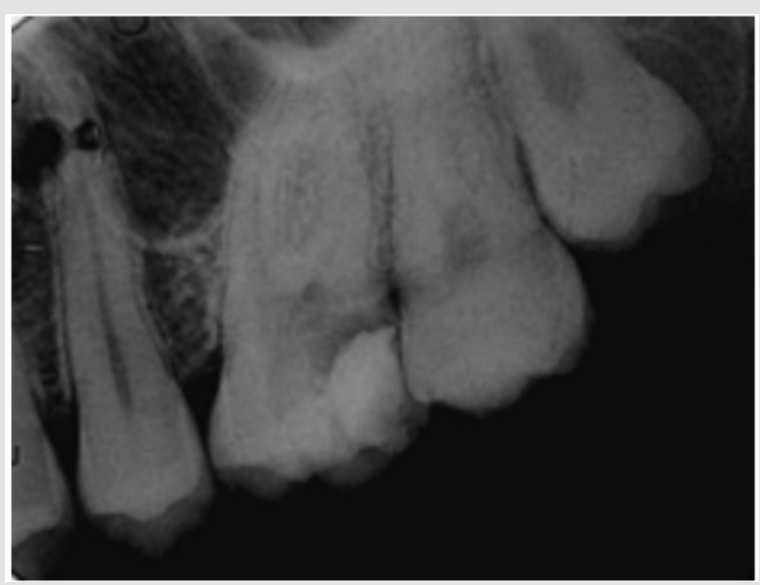

Figure 1: Initial radiograph showing extensive carie and provisional restoration with infiltration.

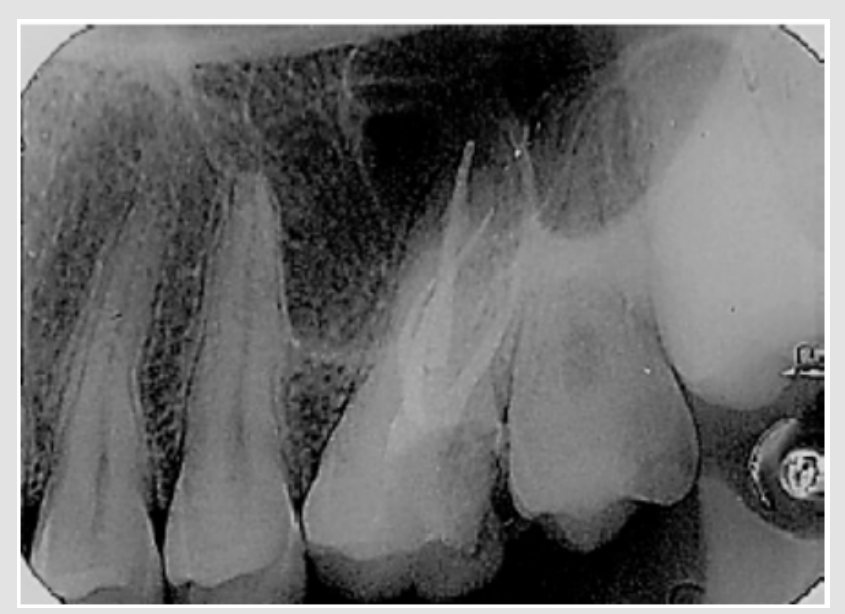

Figure 2: Final radiograph of endodontic treatment.

\section{Case 2}

Patient M.A.R., female, 27 years old, went to Endodontic Specialization to treat the first right maxillary molar. The emergency treatment was done in a health Center one month ago. Radiography was performed (Figure 3) and the clinical examination verified 
the permanence of the fistula (Figure 4). After endodontic access and irrigation with $2.5 \%$ sodium hypochlorite (Iodontosul, Porto Alegre, Brazil), the MB2 was localized with \# $10 \mathrm{C}$ pilot file (VDW, Munich, Germany) (Figures 5 \& 6). Root canal system exploration and electronic working length were performed (Romiapex A-15, Romidan Ltd, Kiryat Ono, Israel). After Glide Path with Proglider was done (Dentisply-Maillefer, Switzerland) and preparation of all channels with Wave One Gold Primary (Dentisply-Maillefer, Switzerland) (Figure 7) The smear layer was removed and calcium hydroxide intracanal medication was done (SS WHITE, Rio de Janeiro, Brazil) and glass ionomer sealing (SS WHITE, Rio de Janeiro, Brazil) were placed. .Patient returns after 40 days, and on clinical examination, fistula regression is observed (Figure 4). In the second appointment, the MB1, MB2 and distal root were enlarged with Wave One Gold Medium ( Dentisply-Maillefer, Suiça) and palatine root has been expanded with Wave One Gold Large (Dentisply-Maillefer, Switzerland), smear layer was removed and obturation performed (Figures 8 \& 9).

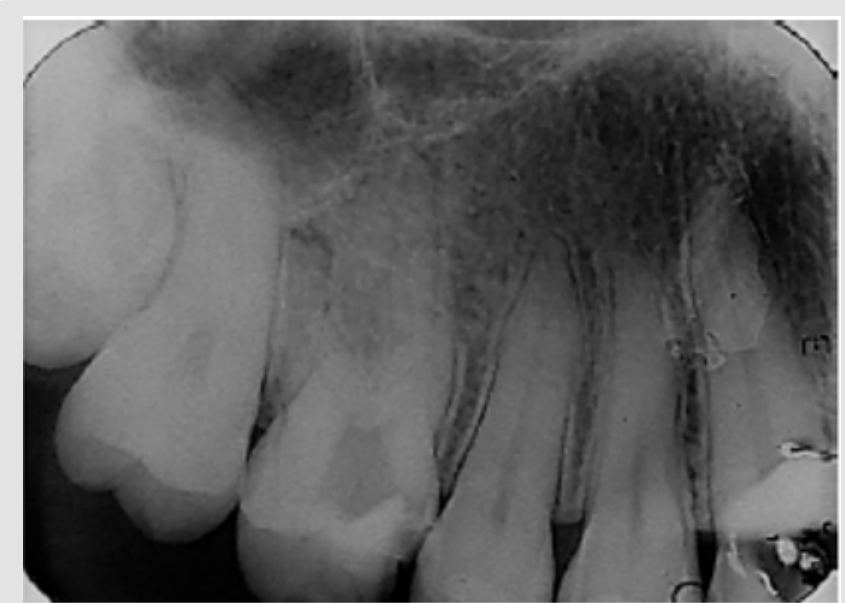

Figure 3: Initial radiograph showing the emergency treatment done in the health center one month ago.

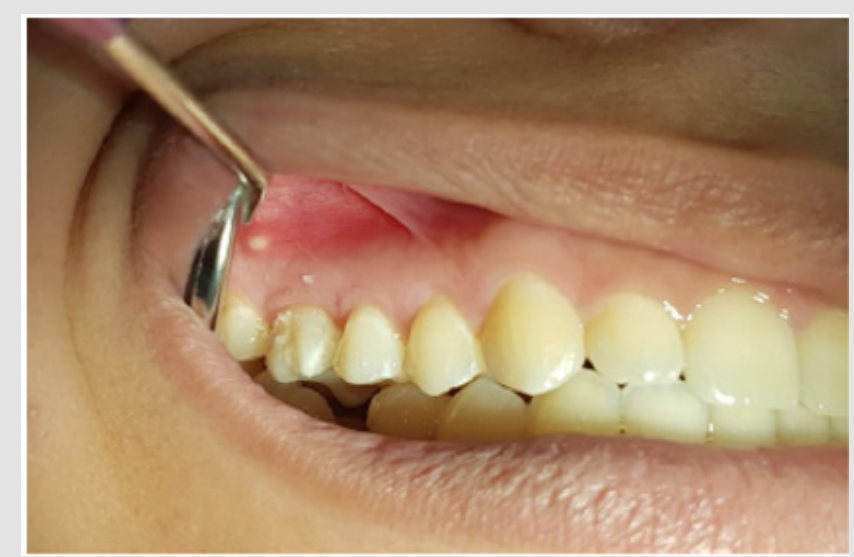

Figure 4 .

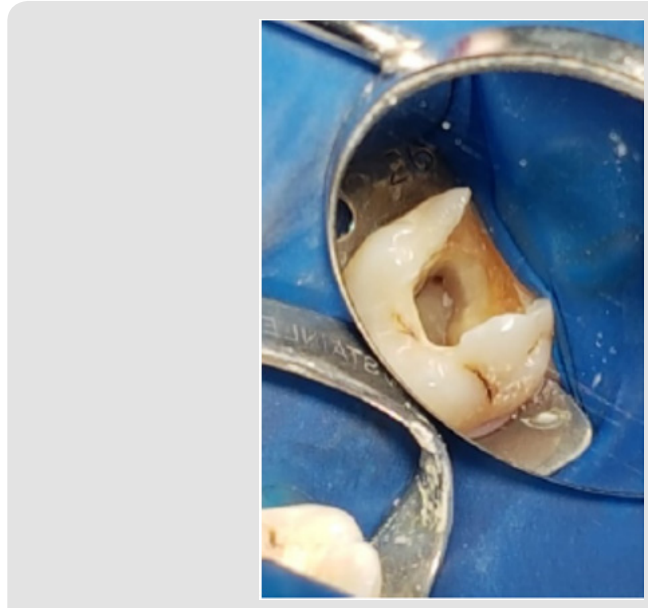

Figure 5: Maxilary right mollar with MB1 located in emergency care.

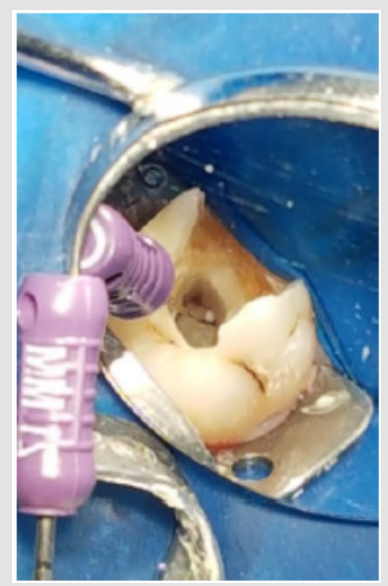

Figure 6: photograph showing the location of the MB2 with C-pilot \# 10 file.

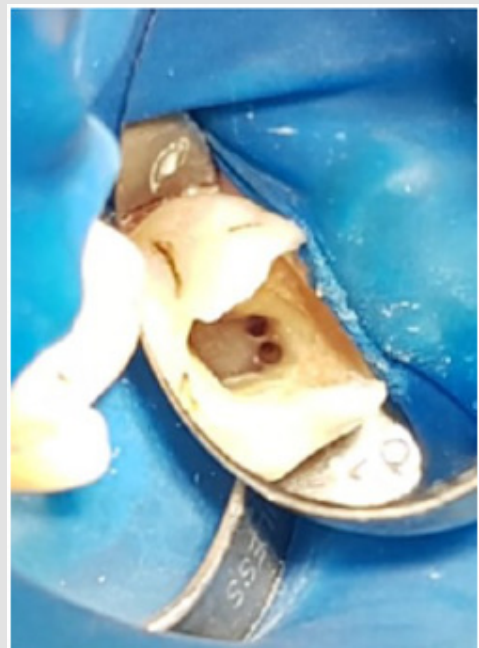

Figure 7: Maxillary right molar after mechanical chemical preparation, showing MB1 and MB2. 


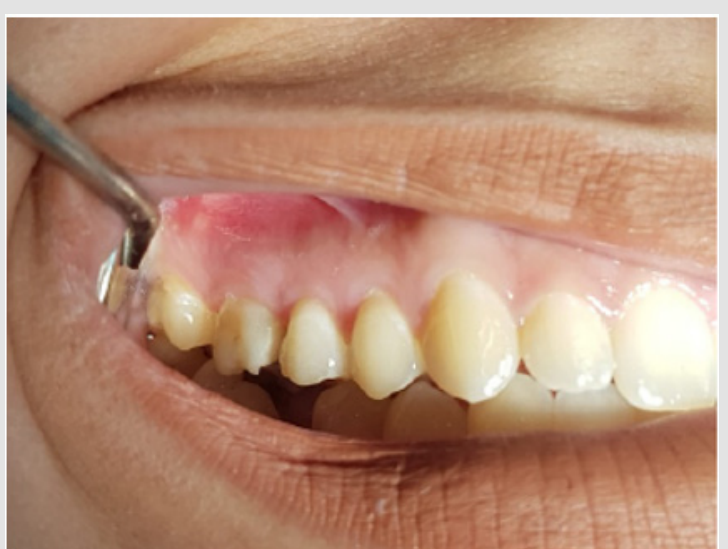

Figure 8: Clinical situation after forty days of calcium hydroxide medication, showing regression of the fistula.

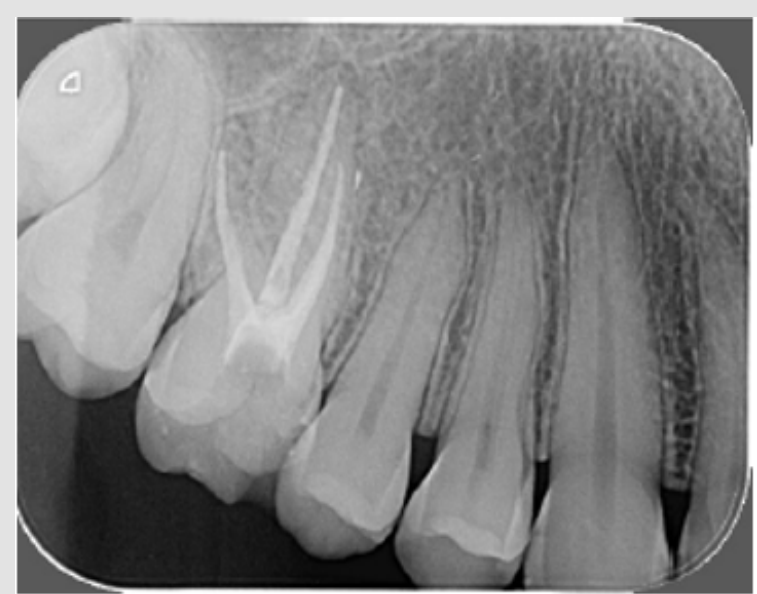

Figure 9: Final radiograph of endodontic treatment.

\section{Discussion}

Endodontic treatment of the upper first molars encourages the operator to locate and the second buccal mesial root canal, known as the second buccal mesial canal or MB2, which is present in $90 \%$ of situations $[13,14]$. It is evident that in the two clinical cases presented, the localization of this channel was performed with the C-pilot \# 10 files, which is one of the resources currently available for identification and initial negotiation of the referred channel [33-39]. In case two, during emergency care there was no localization of MB2, and fistula persisted, which suggests that failure to find this could lead to failure as previously reported $[5,6]$. Adequate preparation and negotiation possibly fistula regression as well as the intracanal medication used (Calcium hydroxide) which has antimicrobial properties and an important role in inactivating LPS produced by Gram negative bacteria [40-45]. The glide path was done with manual files on case 1 and with Proglider instrument in case two (Dentisply-Maillefer, Switzerland). Some authors $[46,47]$ have reported that the mechanical glide path is easier and safer to perform pre-enlargement while maintaining the original canal curvature, but also reduced the frequency and intensity of postoperative complications such as pain. and flare ups. A recent study [48] comparing the torsion properties of various mechanized glide path instruments showed that Logic 25.01 (Easy, Belo Horizonte, Brazil) had the highest torsional force.

It should be noted that in case two, that was pulp necrosis with fistula, we chose to enlarge the foramen of the buccal canals to medium (\#35) and palatine canal to large (\#45), due to the need for decontamination. In addition to conservative expansion, passive ultrasonic irrigation (PUI) and Easy Clean (Easy Dental Equipment, Belo Horizonte, Brazil) are tools that enhance the action of irrigating solutions $[32,49]$ and their use promotes greater cleaning. of the canal and isthms [50]. In both cases, we did not request preoperative Cone Beam Tomography because the patients treated have a poor socioeconomic condition. In addition, we agree with Hiebert et al. [14] that we should only order a Cone Beam Tomography in cases where MB2 is not clinically located. In both cases, we localized MB2 clinically and negotiate without using this feature that our patients do not always have access to. We agree with the various authors $[3,10,32]$ that removal of the dentin shoulder under which the MB2 is located is greatly facilitated with the use of ultrasonic inserts. The reported cases will be followed clinically and radiographically, following the literature $[51,52]$ in Endodontic Specialization.

\section{Conclusion}

The knowledge of teeth internal anatomy is critical to the success of endodontic treatment. This paper reported two clinical cases where MB2 was successfully located and negotiated, even without the aid of more sophisticated equipment. We conclude that in endodontic treatment of maxillary molars, the endodontist should always look for MB2, using all available, accessible and necessary tools for each case.

\section{References}

1. Cleghorn BM, Christie WH, Dong CCS (2006) Root and root canal morphology of the human permanent maxillary first molar: a literature review. J Endod 32(9): 813-821.

2. Parker J, Mol A, Rivera EM, Tawil P (2017) CBCT uses in clinical endodontics: the effect of CBCT on the ability to locate MB2 canals in maxillary molars. Int Endod J 50(12): 1109-1115.

3. Das S, Warhadpande MM, Redij SA, Jibhkate NG, Sabir H (2015) Frequency of second mesiobuccal canal in permanent maxillary first molars using the operating microscope and selective dentin removal: A clinical study. Contemp Clin Dent 6(1): 74-78.

4. Görduysus MO, Görduysus M, Friedman S (2001) Operating microscope improves negotiation of second mesiobuccal canals in maxillary molars. J Endod 27(11): 683-686.

5. Cantatore G, Berutti E, Castellucci A (2006) Missed anatomy: frequency and clinical impact. Endod Top 15(1): 3-31.

6. Wolcott J, Ishley D, Kennedy W, Johnson S, Minnich S (2002) Clinical investigation of second mesiobuccal canals in endodontically treated and retreated maxillary molars. J Endod 28(6): 477-479.

7. Karabucak B, Bunes A, Chehoud C, Kohli MR, Setzer F (2016) Prevalence of Apical Periodontitis in Endodontically Treated Premolars and Molars with Untreated Canal: A Cone-beam Computed Tomography Study. J Endod 42(4): 538-541.

8. Nascimento EHL, Gaêta-Araujo H, Andrade MFS, Freitas DQ (2018) Prevalence of technical errors and periapical lesions in a sample of endodontically treated teeth: a CBCT analysis. Clin Oral Investig 22(7): 2495-2503. 
9. Hasan M, Raza Khan F (2014) Determination of frequency of the second mesiobuccal canal in the permanent maxillary first molar teeth with magnification loupes (× 3.5). Int J Biomed Sci IJBS 10(3): 201-207.

10. Alaçam T, Tinaz AC, Genç O, Kayaoglu G (2008) Second mesiobuccal canal detection in maxillary first molars using microscopy and ultrasonics. Aust Endod JJ Aust Soc Endodontology Inc 34(3): 106-109.

11. Yang YM, Guo B, Guo LY, Yang Y, Hong X, et al. (2016) CBCT-Aided Microscopic and Ultrasonic Treatment for Upper or Middle Thirds Calcified Root Canals. BioMed Res Int. 2016: 4793146.

12. Mamoun JS (2016) The maxillary molar endodontic access opening: A microscope-based approach. Eur J Dent 10(3): 439-446.

13. Studebaker B, Hollender L, Mancl L, Johnson JD, Paranjpe A (2018) The Incidence of Second Mesiobuccal Canals Located in Maxillary Molars with the Aid of Conebeam Computed Tomography. J Endod 44(4): 565570 .

14. Hiebert BM, Abramovitch K, Rice D, Torabinejad M (2017) Prevalence of Second Mesiobuccal Canals in Maxillary First Molars Detected Using Cone-beam Computed Tomography, Direct Occlusal Access, and Coronal Plane Grinding. J Endod 43(10): 1711-1715.

15. Karapinar Kazandag M, Basrani BR, Friedman S (2010) The operating microscope enhances detection and negotiation of accessory mesial canals in mandibular molars. J Endod 36(8): 1289-1294.

16. Baratto Filho F, Zaitter S, Haragushiku GA, de Campos EA, Abuabara A, et al. (2009) Analysis of the internal anatomy of maxillary first molars by using different methods. J Endod 35(3): 337-342.

17. Zuolo ML, Carvalho MC, De Deus G (2015) Negotiability of Second Mesiobuccal Canals in Maxillary Molars Using a Reciprocating System. J Endod 41(11): 1913-1917.

18. Plotino G, Giansiracusa Rubini A, Grande NM, Testarelli L, et al. (2014) Cutting efficiency of Reciproc and waveOne reciprocating instruments. J Endod 40(8): 1228-1230.

19. De Deus G, Arruda TEP, Souza EM, Neves A, Magalhães K, et al. (2013) The ability of the Reciproc R25 instrument to reach the full root canal working length without a glide path. Int Endod J 46(10): 993-998.

20. Buchanan LS (2001) The standardized-taper root canal preparationpart 5. GT file technique in small root canals. Int Endod J 34(3): 244-249.

21. Mohammadzade Akhlaghi N, Fazlyab M (2017) Treatment of a FourRooted Maxillary Second Molar Detected with Cone-Beam Computed Tomography. J Dent Tehran Iran. 14(2): 100-104.

22. Umer F (2014) Maxillary first molar with five canals. BMJ Case Rep : 2014.

23. Patel S, Patel P (2012) Endodontic management of maxillary second molar with two palatal roots: a report of two cases. Case Rep pp. 4.

24. Corcoran J, Apicella MJ, Mines P (2007) The effect of operator experience in locating additional canals in maxillary molars. J Endod 33(1): 15-17.

25. Reis AG de AR, Grazziotin Soares R, Barletta FB, Fontanella VRC, Mahl CRW (2013) Second canal in mesiobuccal root of maxillary molars is correlated with root third and patient age: a cone-beam computed tomographic study. J Endod 39(5): 588-592.

26. Spagnuolo G, Ametrano G, Formisano A, Simeone M, Riccitiello F, et al. (2012) Microcomputed tomography analysis of mesiobuccal orifices and major apical foramen in first maxillary molars. Open Dent J 6: 118-125.

27. Betancourt P, Navarro P, Muñoz G, Fuentes R (2016) Prevalence and location of the secondary mesiobuccal canal in 1,100 maxillary molars using cone beam computed tomography. BMC Med Imaging de 16(1): 66.

28. (2015) Special Committee to Revise the Joint AAE/AAOMR Position Statement on use of CBCT in Endodontics. AAE and AAOMR Joint Position Statement: Use of Cone Beam Computed Tomography in Endodontics 2015 Update. Oral Surg Oral Med Oral Pathol Oral Radiol 120(4): 508512.
29. Yoshioka T, Kikuchi I, Fukumoto Y, Kobayashi C, Suda H (2005) Detection of the second mesiobuccal canal in mesiobuccal roots of maxillary molar teeth ex vivo. Int Endod J 38(2): 124-128.

30. Patel S, Rhodes J (2007) A practical guide to endodontic access cavity preparation in molar teeth. Br Dent J 203(3): 133-140.

31. Schwarze T, Baethge C, Stecher T, Geurtsen W (2002) Identification of second canals in the mesiobuccal root of maxillary first and second molars using magnifying loupes or an operating microscope. Aust Endod J J Aust Soc Endodontology Inc 28(2): 57-60.

32. Plotino G, Pameijer CH, Grande NM, Somma F (2007) Ultra sonics in endodontics: a review of the literature. J Endod 33(2): 81-95.

33. Fachin EV, Wenckus CS, Aun CE (1995) Retreatment using a modified-tip instrument. J Endod 21(8): 425-428.

34. Siddiqui SH (2014) Management of pulp canal obliteration using the Modified-Tip instrument technique. Int J Health Sci 8(4): 426-428.

35. Kobayashi C (1997) Penetration of constricted canals with modified K files. J Endod 23(6): 391-393.

36. Schäfer E, Erler M, Dammaschke T (2006) Comparative study on the shaping ability and cleaning efficiency of rotary $M$ two instruments. Part 2. Cleaning effectiveness and shaping ability in severely curved root canals of extracted teeth. Int Endod J 39(3): 203-212.

37. Lopes HP, Elias CN, Mangelli M, Lopes WSP, Amaral G, et al. (2012) Buckling resistance of pathfinding endodontic instruments. J Endod 38(3): 402-404.

38. Lopes HP, Elias CN, Siqueira JF, Soares RG, Souza LC, et al. (2012) Mechanical behavior of pathfinding endodontic instruments. J Endod 38(10): 1417-1421.

39. Adiguzel M, Tufenkci P (2018) Comparison of the ability of Reciproc and Reciproc Blue instruments to reach the full working length with or without glide path preparation. Restor Dent Endod 43(4): e41.

40. Brito M, Moreira G, Normanha JA, Camilo CC, Savioli RN, et al. (2013) Midbuccal canals of maxillary molars evaluated by cone-beam computed tomography: endodontic management of two cases. Braz Dent J 24(6): 575-579.

41. Venumuddala VR, Moturi S, Satish SV, Chakravarthy BK, Malapati S (2017) Endodontic Management of a Maxillary First Molar with Seven Root Canal Systems Evaluated Using Cone-Beam Computed Tomography Scanning. J Int Soc Prev Community Dent 7(5): 297-300.

42. Hulsmann M, Peters OA, Dummer PMH (2005) Mechanical preparation of root canals: shaping goals, techniques and means. Endod Top 10(1): 30-76.

43. Al-Hadlaq SMS, Aljarbou FA, AlThumairy RI (2010) Evaluation of cyclic flexural fatigue of M-wire nickel-titanium rotary instruments. J Endod 36(2): 305-307.

44. Ye J, Gao Y (2012) Metallurgical characterization of M-Wire nickeltitanium shape memory alloy used for endodontic rotary instruments during low-cycle fatigue. J Endod 38(1): 105-107.

45. Sjögren U, Figdor D, Spångberg L, Sundqvist G (1991) The antimicrobial effect of calcium hydroxide as a short-term intracanal dressing. Int Endod J 24(3): 119-125.

46. Berutti E, Cantatore G, Castellucci A, Chiandussi G, Pera F, et al. (2009) Use of Nickel-Titanium Rotary PathFile to Create the Glide Path: Comparison with Manual Preflaring in Simulated Root Canals. J Endod 35(3): 408-412.

47. Pasqualini D, Mollo L, Scotti N, Cantatore G, Castellucci A, et al. (2012) Postoperative pain after manual and mechanical glide path: a randomized clinical trial. J Endod 38(1): 32-36.

48. Alcalde MP, Duarte MAH, Bramante CM, Tanomaru-filho M, Vasconcelos $\mathrm{BC}$, et al. (2018) Torsional fatigue resistance of pathfinding instruments manufactured from several nickel-titanium alloys. Int Endod J 51(6): 697-704. 
49. Marques AC, Aguiar BA, Frota LM, Guimarães BM, Vivan RR, et al. (2018) Evaluation of Influence of Widening Apical Preparation of Root Canals on Efficiency of Ethylenediaminetetraacetic Acid Agitation Protocols: Study by Scanning Electron Microscopy. J Contemp Dent Pract 19(9): 1087-1094.

50. Gutarts R, Nusstein J, Reader A, Beck M (2005) In Vivo Debridement Efficacy of Ultrasonic Irrigation Following Hand-Rotary Instrumentation in Human Mandibular Molars. J Endod o de março de 31(3): 166-170.

ISSN: 2574-1241

DOI: 10.26717/BJSTR.2019.21.003592

Larissa Magnus Klassmann. Biomed J Sci \& Tech Res

(C) This work is licensed under Creative

Submission Link: https://biomedres.us/submit-manuscript.php
51. Burkovski A, Karl M (2018) Lack of evidence for the necessity of root canal obturation. Quintessence Int Berl Ger 50(1): 2-8.

52. Bergenholtz G, Spångberg L (2004) Controversies in Endodontics. Crit Rev Oral Biol Med Off Publ Am Assoc Oral Biol 15(2): 99-114.

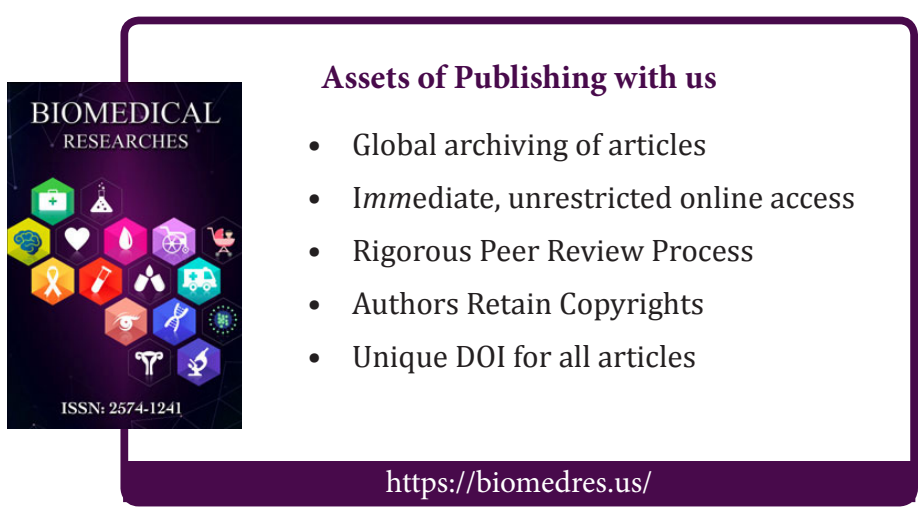

